\title{
Clinical and ultrastructural findings in an ataxic variant of Kufor-Rakeb syndrome
}

\author{
Anna Pietrzak ${ }^{1}$, Magdalena Badura-Stronka², Tiia Kangas-Kontio ${ }^{3}$, Paulina Felczak ${ }^{4}$, Wojciech Kozubski ${ }^{5}$, \\ Anna Latos-Bielenska ${ }^{2}$, Teresa Wierzba-Bobrowicz ${ }^{4}$, Jolanta Florczak-Wyspianska ${ }^{5}$ \\ ${ }^{1}$ Chair and Department of Neurology, Poznan University of Medical Sciences, Poznan, Poland, ${ }^{2}$ Department of Medical Genetics, \\ Poznan University of Medical Sciences, Poznan, Poland, ${ }^{3}$ Blueprint Genetica, Helsinki, Finland, ${ }^{4}$ Department of Neuropathology, \\ Institute of Psychiatry and Neurology, Warsaw, Poland, ${ }^{5} \mathrm{Chair}$ and Department of Neurology, Poznan University of Medical Sciences, \\ Poznan, Poland
}

\begin{abstract}
Introduction: Kufor-Rakeb syndrome (KRS) is a rare autosomal recessive neurodegenerative disorder manifesting as juvenile-onset atypical parkinsonism with pyramidal signs, supranuclear gaze palsy, dementia and characteristic minimyoclonus, with a notable phenotype variability. The responsible gene ATP13A2 was also associated with hereditary spastic paraplegia, uncomplicated early - or late-onset parkinsonism and a form of neuronal ceroid lipofuscinosis. We present clinical and ultrastructural findings in a 28-year-old woman with novel biallelic ATP13A2 mutations. Material and methods: An ultrastructural study of the skin and muscle sample was carried out. Sequence analysis of all protein coding exons and exon-intron boundaries of genes was performed on patient's genomic DNA. A proprietary oligonucleotide-selective sequencing method was used for capturing genomic targets and sequencing was performed using Illumina sequencing system.

Results: The patient presented with juvenile-onset progressive parkinsonian syndrome and cognitive deterioration, accompanied by mild spastic paraplegia, supranuclear gaze palsy, cerebellar syndrome, peripheral neuropathy and fine myoclonus. Plentiful and varied osmiophilic deposits were found in skin and muscle biopsy. Sequence analysis identified two novel heterozygous variants in ATP13A2: a nonsense variant c.2209C CT, p. $\left(G \ln 737^{\star}\right)$ and a 2-bp deletion c.2366_2367delTC, p.(Leu789Argfs*15) causing a frameshift leading to a premature stop codon. Oral levodopa treatment was initiated resulting in marked improvement of bradykinesia, rigidity, speech and swallowing.

Conclusions: We report two novel ATP13A2 pathogenic mutations, further expanding the phenotype of Kufor-Rakeb syndrome with the unusual features of ataxia and polyneuropathy. We thoroughly describe ultrastructural findings and document a meaningful response to levodopa.
\end{abstract}

Key words: ATP13A2, PARK9, Kufor-Rakeb syndrome, Parkinson's disease, ataxia.

\section{Introduction}

Kufor-Rakeb syndrome (KRS) is a rare autosomal recessive, juvenile-onset atypical parkinsonism [32].
It is caused by loss-of-function mutations in the ATP13A2 gene (also known as PARK9) which encodes a lysosomal 5P-type ATPase. Affected individuals usually present in the second or third decade

\section{Communicating author}

Anna Pietrzak, MD, Chair and Department of Neurology, Poznan University of Medical Sciences, 49 Przybyszewskiego St., 60-355 Poznan, Poland, e-mail: apiet@o2.pl 
with levodopa-responsive parkinsonian syndrome, accompanied by pyramidal signs, supranuclear gaze palsy and dementia.

Besides the complete KRS phenotype, mutations in ATP13A2 were found to cause a less severe disease without a cognitive deficit and pyramidal signs [12]. Single heterozygous mutations were reported in milder cases with early-onset parkinsonism $[4,24,26]$ and several studies found an association between certain ATP13A2 variants and a heightened risk of apparently sporadic, late-onset Parkinson's disease $[32,36]$. Further widening the phenotype spectrum, a family with juvenile-onset neuronal ceroid-lipofuscinosis (NCL) associated with homozygous ATP13A2 mutation was described in Belgium [5]. Small histopathological studies were done in the classic KRS kindreds, but in a few available peripheral tissue biopsies, lamellar inclusions were also found $[25,31]$.

Here, we present a newly identified KRS case from Poland, a compound heterozygote with two novel mutations in ATP13A2: c.2366_2367delTC, p.(Leu789Argfs $\left.{ }^{\star} 15\right)$, a frameshift mutation leading to a premature stop codon, and a nonsense variant c.2209C >T, p. $\left(G \ln 737^{*}\right)$. Electron-dense deposits consistent with neuronal ceroid lipofuscinosis were found in the skin and muscle biopsy.

\section{Material and methods}

The patient's caregivers have signed informed consent to the anonymous use of her clinical data in further medical research.

\section{Molecular testing}

Total genomic DNA was extracted from peripheral blood of the patient. DNA quality and quantity were assessed using a fluorometric electrophoresis method.

Sequence analysis of all protein coding exons and exon-intron boundaries of genes of the Blueprint Genetics Comprehensive Metabolism Panel (version 2, Aug 14, 2017) was performed [3].

Extracted total genomic DNA was mechanically fragmented and enzymatically end-repaired. DNA adapters were added using a ligation-based method and the sequencing library was amplified using PCR. Quality and quantity of the sequencing library DNA were assessed through electrophoresis and fluorometric analyses, respectively. A proprietary Oligonu-
cleotide-Selective Sequencing (OS-Seq) method was used for capturing genomic targets and sequencing was performed using an Illumina sequencing system.

Raw sequence reads were filtered to exclude reads with ambiguous base calls and trimmed from the 3' ends based on base call quality and presence of adapter, poly-A or capture oligo sequences. The remaining high-quality reads were mapped to the human genome reference sequence ( $\mathrm{Hg} 19)$. Single nucleotide variants (SNVs) and short insertions and deletions (INDELs) were identified using a proprietary data analysis pipeline. Identified variants were annotated using allelic frequencies from large population studies (e.g. 1000 Genomes Project [14] and the Exome Aggregation Consortium (ExAC) and Genome Aggregation Database [22]), by matching with various genotype-phenotype association databases, e.g. Human Gene Mutation Database (HGMD [41]), ClinVar [21]) as well as by searching from an in-house curated database of previously reported variants.

The clinical evaluation team of Blueprint Genetics assessed the pathogenicity of the identified variants by evaluating allele frequency, in silico predictions, the annotations from public variant databases and matches in the in-house mutation database and related medical literature. Sequencing data was manually inspected to confirm the variant findings. Identified variants were confirmed using direct Sanger sequencing of the PCR amplicons.

\section{Transmission electron microscopy}

The ultrastructural investigations were performed on the skin and muscle biopsy samples derived from biceps. Ultrastructural studies were carried out on skin cells including eccrine sweat glands and intradermal nerve fibres. Skeletal muscle fibers and small blood vessels, e.g. capillaries, were also analysed. Pathological changes for each individual cell type were observed.

For electron microscopic evaluation, small fragments of tissues were fixed in $2.5 \%$ glutaraldehyde solution in cacodylate buffer $\mathrm{pH} 7.4$, and postfixed in $1 \%$ osmium tetroxide solution in the same buffer. After dehydration in a graded ethanol alcohol series and propylene oxide, specimens were embedded in Spurr resin. Semithin sections were stained with toluidine blue to choose appropriate areas. Ultrathin sections were contrasted with uranyl acetate and lead citrate. The sections were examined and pho- 
tographed with transmission electron microscope (TEM), JEOL model 140 in Nencki Institute of Experimental Biology at the Polish Academy of Sciences.

\section{Results}

\section{Clinical findings}

A 28-year-old woman was referred to our clinic for progressive motor and cognitive impairment, which was found to represent a juvenile-onset parkinsonian syndrome with spastic tetraparesis, progressive cognitive deterioration, psychosis, supranuclear gaze palsy and myoclonias.

She was born as the first child, at term, from an uneventful pregnancy and labour, with body weight of $3400 \mathrm{~g}$ and APGAR score of 10 . Her parents were unrelated, her family history unremarkable. She has two younger unaffected sisters.

At the age of 6 months, she ceased to sit unsupported and started to cross her lower limbs when held upright, possibly as the first manifestation of spastic paraplegia, as the examination at 11 months revealed calcaneal tendon contractures and spastic tetraplegia. Rehabilitation was initiated. She began to stand on her own at 13 months and walk at 20. At that time, she was talking with simple sentences and quickly developing her language skills. In primary school, she initially performed well, but was noted to run slower than the other children. It was not until the age of 10 when her learning difficulties, particularly in mathematics, became apparent. She tried to continue her education in high school, but switched to vocational school after a year. At 17 , she began to experience recurrent falls. Although the falls had no features indicative of a seizure disorder, she was diagnosed with epilepsy and treated with valproate, with no effect on the falls. Her motor deficiency continued to progress, the gait became shuffling. Neurological assessment at the age of 23 revealed tongue tremor, dysarthric, monotonous speech, limb dysmetria and dysdiadochokinesis, positive Tromner sign and wide-based gait. In MRI, cerebellar and frontal cortical atrophy was present. Nerve conduction study was normal at that time. Chromosomal aberrations, SCA 1, 2 and 3, Wilson disease, Niemann-Pick disease ( $A$ and $B$ type) were subsequently ruled out.

At 25 years of age, she became bedridden and additional symptoms of dysphagia, excessive drooling and psychosis emerged. On neurological exam- ination, limited upgaze, severe bradykinesia and quadrupedal spasticity was present. The psychotic symptoms included persecutory delusions of a poorly defined imminent threat and auditory hallucinations (scary voices); these symptoms were controlled with olanzapine. A percutaneous endoscopic gastrostomy was planted to counter dysphagia. Nerve conduction studies revealed an axonal polyneuropathy.

At admission to our Department of Neurology, the patient presented with prominent psychomotor slowing. She only gave delayed, quiet, single-word answers, consistent with severe hypokinetic dysarthria. The face was markedly hypomimic, with dystonic smile present most of the time, occasional blepharoclonus, perioral myoclonias and postural tongue tremor. Supranuclear gaze palsy was noted, with restriction of volitional upgaze, which could be overcome by doll's eyes manoeuvre. Upward saccadic movements were not possible at all, while downward and horizontal saccades were delayed and hypometric. Tracking eye movements appeared grossly smooth. Glabellar and bilateral palmomental reflexes were present. Axial rigidity predominated over that of the extremities. Limb strength was MRS 4 in upper limbs and 3 and 3.5 in the left and right lower limb, respectively. Tendon reflexes were exaggerated, and pathological signs of Jacobsohn, Sterling and Rossolimo were bilaterally present. The limbs were severely bradykinetic (UPDRS grade 4) and featured both lead pipe rigidity (UPDRS grade 3 ) and spasticity, with a trace of cogwheel rigidity at the wrists and ankles, but no visible rest tremor. An action myoclonus of the fingers of the hands was observed. The upper limbs were ataxic (dysmetric finger-to-nose with intention tremor), while spasticity and weakness prevented assessment of ataxia in the lower extremities. The sensory examination was normal. The patient was no longer able to rise from recumbency on her own and could only walk a few wide-based steps with considerable support. She expressed intense fear of falling.

A brain magnetic resonance imaging study (MRI) revealed cerebellar and brainstem atrophy as well as a mild cerebral atrophy.

At the time of assessment, she was being treated with levodopa with benserazide $50 \mathrm{mg}+12.5 \mathrm{mg}$ t.i.d. for a month. Psychiatric symptoms were controlled with quetiapine $25 \mathrm{mg}$ b.i.d. and olanzapine $2.5 \mathrm{mg}$ q.d.p.m. 
The levodopa dose was titrated over a week to $100 \mathrm{mg}+25 \mathrm{mg}$ q.i.d.; an attempt at further increase caused hypotension and re-emergence of persecutory delusions. At discharge, rigidity did decrease markedly, but was no change in gait, at least in part due to anxiety. Paroxetine was initiated to address this.

At follow-up appointment after 2 months, while the patient was still hesitant to walk, other symptoms showed significant improvement: speech was more intelligible and swallowing difficulties were largely alleviated, allowing the patient to eat by mouth and use her PEG only occasionally. Levodopa and antipsychotic medication was maintained at the current doses. We look forward to the next visit with curiosity and a degree of cautious optimism.

\section{Molecular testing}

Sequence analysis identified two novel heterozygous variants in ATP13A2: a nonsense variant c.2209C $>T, \quad p .\left(G \ln 737^{\star}\right)$ and a 2-bp deletion c.2366_2367delTC, p.(Leu789Argfs*15). ATP13A2 c.2366_2367delTC, p.(Leu789Argfs*15) generates a frameshift leading to a premature stop codon in a new reading frame (802 out of normal 1180 amino acids). It is predicted that both variants cause loss of normal protein function either through protein truncation or nonsense-mediated mRNA decay. The variants have not been observed in large reference population cohorts of Genome Aggregation Database (> 120,000 exomes and >15,000 genomes), and to our knowledge, the variants have not been reported in the literature or in HGMD or ClinVar databases.

\section{Transmission electron microscopy}

\section{Skin}

In eccrine sweat gland epithelial cells, numerous NCL-specific lipopigment deposits were present, in the form of extensive aggregations of electron dense material, rounded but irregular in shape and separated from the cytoplasm by a membrane. Most frequently observed was a combination of homogeneous uniform dark structures and heterogeneous material, such as "zebra-like" inclusions (Fig. 1A): rounded or oval, membrane-enveloped bodies with a striped texture. Sporadically, granular osmiophilic deposits (GROD) were present.

"Zebra-like" inclusions were also occasionally found in the nerve processes of myelinated nerves (Fig. 1B).

\section{Muscle}

Ultrastructural studies of skeletal muscle fibres showed the presence of numerous NCL-specific lipopigment deposits. These osmiophilic bodies occurred most frequently in clusters and were found in satellite cells and fibroblasts.

The muscle satellite cells contained several forms of storage material: large oval dark and homogeneous inclusions separated from the sarcoplasm by a membrane, heterogeneous material resembling loose texture GROD storage (Fig. 2A) and oval structures with numerous concentric or parallel membrane configurations. Striped "zebra-like" inclusions were another type present.

The accumulation of osmiophilic deposits was also apparent in the cytoplasm of fibroblasts located
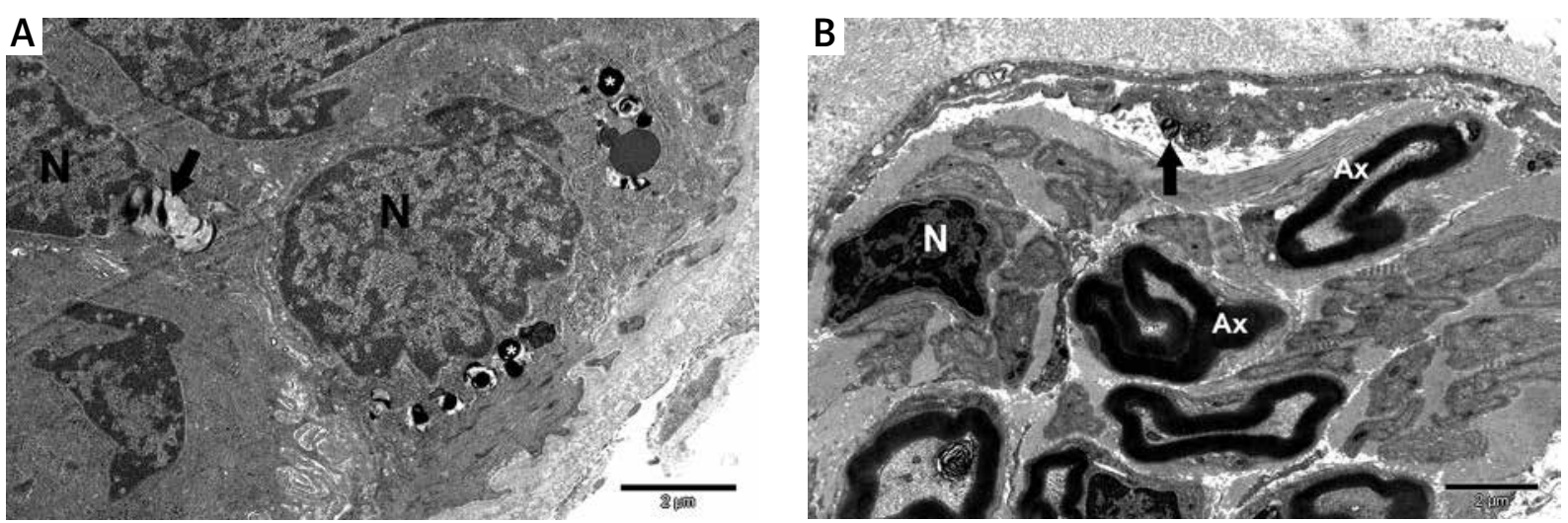

Fig. 1. A) Electron dense (asterisk) and "zebra-like" inclusions (arrow) around the nucleus (N). Dermal eccrine sweat gland epithelial cells. Original magnification 15 000x. B) "Zebra-like" inclusions (arrow). Intradermal nerve Schwann cell. Nucleus (N), axon (Ax). Original magnification 12 000x. 

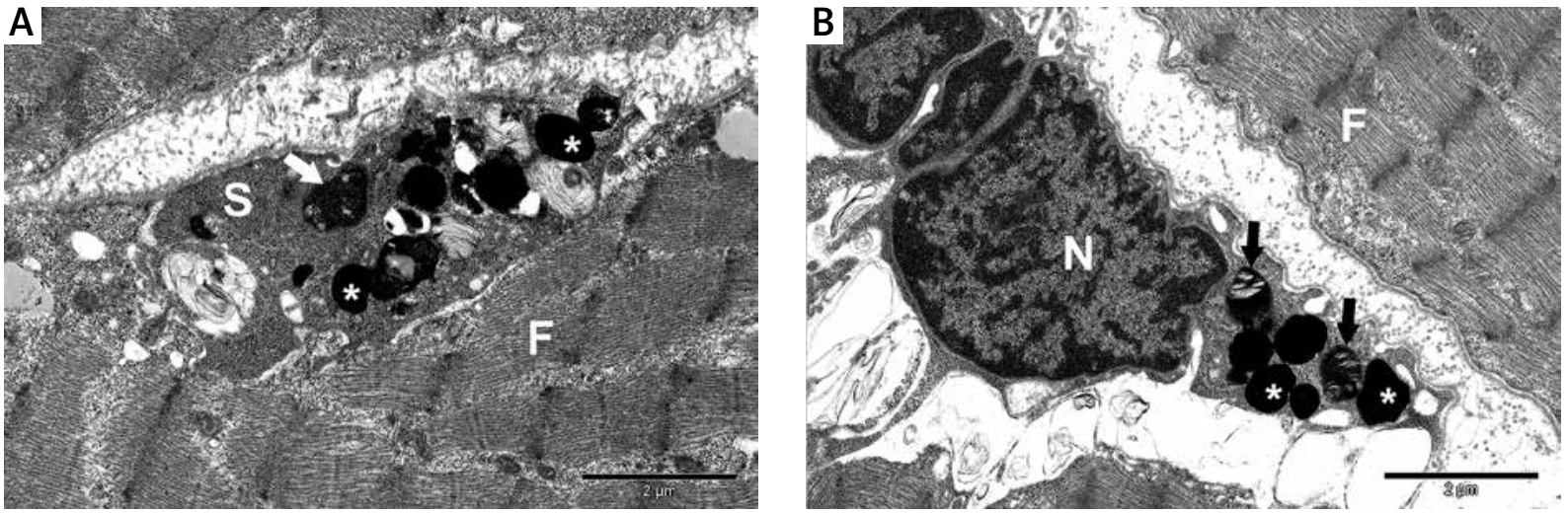

Fig. 2. A) Homogeneous osmiophilic inclusions (asterisk) and GROD (white arrow). Muscle fibre (F) satellite cell (S). Original magnification $20000 \times$. B) Electron dense (asterisk) and "zebra-like" inclusions (arrow), next to the nucleus $(\mathrm{N})$ in a fibroblast. Muscle fibre. Original magnification $20000 \times$.
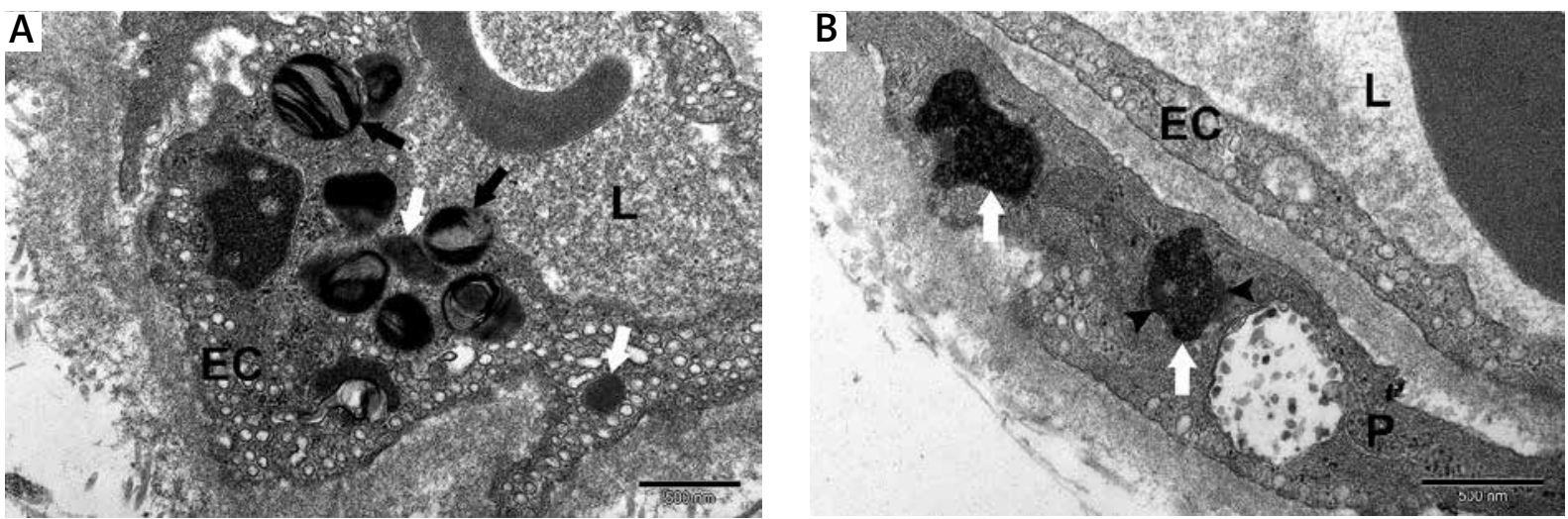

Fig. 3. A) "Zebra-like" inclusions (arrow) and GROD (white arrow) in a capillary endothelial cell (EC). Lumen (L). Original magnification 50 000x. B) Fingerprint profiles (arrowhead) and granular osmiophilic deposit (white arrow) in the cytoplasm of a pericyte (P). Original magnification 60 000x.

between muscle fibres. They included electron dense deposits and "zebra-like" inclusions (Fig. 2B). Some fibroblast processes featured dark lamellar bodies.

\section{Small blood vessels}

Intracytoplasmic dark inclusions have also been identified in endothelium and pericytes of blood capillaries (Fig. 3A). They included homogenous osmiophilic rounded deposits and heterogeneous bodies which included "zebra-like" inclusions and GROD structures (Figs. 3A, B). In pericytes, fingerprint profiles were occasionally observed (Fig. 3B).

\section{Discussion}

\section{Clinical findings}

Kufor-Rakeb disease was first described in an offspring of a consanguineous couple from Kufor-
Rakeb in Jordan [29]. At ages 11-16, the five affected siblings developed rapidly progressive gait disturbance, rigidity and bradykinesia with mask-like faces, upgaze paresis and cognitive deterioration. Later reassessment revealed new features, including facial-faucial-finger minimyoclonus, oculogyric crises and hallucinations [45]. The symptoms initially improved on levodopa, but with time, the response worsened, and levodopa-induced dyskinesias emerged. Meanwhile, a similar syndrome was found in a nonconsanguineous Chilean family. A causative mutation in ATP13A2 was identified, and a different mutation in the same gene was found in the original Jordanian kindred [37]. Since then, several affected families have been reported worldwide (including patients of Belgian [5], South American [2,12], Middle East $[7,24,29,40]$, Far East $[13,30]$ and Inuit [9] origin), most with unique mutations. To this day, KRS 
has been reported in at least 13 kindreds, with no less than 33 affected individuals [13,27,32]. Beyond the core feature of parkinsonism and common presence of spasticity, gaze palsy, myoclonus and dementia, there is marked clinical variability among these cases. An excellent review by Park et al. summarizes their clinical presentations [32].

Gait disturbance and falls, motor and cognitive slowing or mood and behaviour changes are the usual presenting signs. In most, they become apparent in the second or third decade of life, ranging from the age of 7 [38] to 30 [24].

In our patient, a certain degree of spasticity was present from infancy. Visible cognitive deterioration occurred around the age of 10, and the falls became evident at 17, fitting within the usual onset presentation and time range. Assuming 10 as the time of first signs would make ours one of the earlier, yet more indolently progressive courses.

The progression rate is highly variable among the cases. In the original Jordanian kindred, the siblings became bedridden within months; deterioration was also rapid in cases from China [33] and Afghanistan [7]. In other families, it spanned over years [2,9].

Levodopa-responsive parkinsonism is the core feature of KRS. Rigidity predominates over tremor. Unfortunately, the improvement on levodopa is transient and soon, drug-induced dyskinesias emerge. Our patient had no rest tremor, but cogwheel was clearly present in addition to dominating leadpipe rigidity, especially at wrists and ankles. At follow-up, a significant improvement in bradykinesia, rigidity, swallowing and speech was apparent in our patient.

Symptoms almost universally present early in the course of the disease are pyramidal signs, supranuclear gaze palsy and cognitive impairment.

Our patient exhibited the complete set of pyramidal signs, although with Rossolimo instead of Babinski sign.

Supranuclear gaze palsy (especially of upgaze) is almost universal as well. Saccadic eye movements are usually delayed and hypometric. Pursuit is occasionally abnormal as well. Our patient's tracking movements were grossly normal, but there was clear limitation of upward tracking. Saccades to the sides and downwards were hypometric, requiring corrective mini-saccades, and occurred after a clear delay. Upward saccades were not possible.

Cognitive deterioration is apparent in nearly all cases. It is usually noticed together with first motor signs and continues to progress in parallel to other deficits. Late evaluation is difficult due to the usual hypokinetic dysarthria that often reduces speech to single whispered words. Our patient was no different.

Other characteristic symptoms include peculiar facial-faucial-finger minimyoclonus (also present in our patient) and psychiatric disturbances: apathy, social withdrawal, anxiety and psychosis with visuall hallucinations (delusions and auditory hallucinations in our case). Dysarthria and dysphagia are common in later stages and sometimes severe enough to compromise oral feeding.

Other features include dystonia, especially on levodopa, oculogyric crises and occasionally olfactory impairment $[2,19,33]$.

Cerebellar signs were reported in only a few cases. Ataxia was present in two of three Inuit patients [9], interestingly, these patients had only slight global cerebral atrophy. Acerebellar syndrome was apparent in the Belgian KRS/NCL overlap family [5]. A brief poster from the North American physical medicine congress reports KRS siblings with ataxia [18]. On the other hand, a cerebellar syndrome is an integral part of Hereditary spastic paraplegia type 78 (SPG78) [10], where it is present in all affected individuals and accompanied with marked cerebellar atrophy on MRI. Interestingly, out of five affected members, only one showed mild parkinsonian features, but supranuclear gaze palsy was present in two and cognitive deficit in four.

Among KRS families, an axonal polyneuropathy was reported only in the Inuit [9], but, quite intriguingly, axonal or mixed axonal-demyelinating polyneuropathy is present in most of the SPG78 cases [10]. Our patient had a normal nerve conduction study (NCS) at 23. A repeat study at the age of 26 featured an axonal sensory-motor polyneuropathy. Because of considerable discomfort and pain reported during the past procedures, we did not perform another NCS in our clinic.

\section{Molecular mechanism}

ATP13A2 is a P-type ATPase. P-type ATPases are a conserved family of ATP-fuelled cation pumps. They include several well-known transporters, including the ubiquitous $\mathrm{Na}^{+} / \mathrm{K}^{+}$ATPase and the copper pump ATP7B associated with Wilson's disease. In mammals, ATP13A2 is predominantly expressed in the brain, especially in substantia nigra. Wild-type 
ATP13A2 localizes to late endosomes and lysosomes [44]. Its substrates are unknown, but the enzyme appears to be involved in heavy metal ion homeostasis, including $\mathrm{Mn}^{2+}$ and $\mathrm{Zn}^{2+}$. Deletion of YPK9p, the yeast ATP13A2 orthologue, increases sensitivity to $\mathrm{Cd}^{2+}, \mathrm{Mn}^{2+}, \mathrm{Ni}^{2+}$ and $\mathrm{Se}^{2+}[15,39]$. Conversely, overexpression also causes susceptibility to $\mathrm{Ni}$ and cd toxicity [34].

Mutations in ATP13A2 lead to mitochondrial $[10,17]$ and lysosomal dysfunction, including impaired acidification and decreased autophagosome degradation $[8,10]$. Impaired lysosomal capacity leads to increased $\alpha$-synuclein accumulation and thus contributes to Parkinson's disease pathogenesis $[8,43]$. In a rat midbrain neuron culture, ATP13A2 co-transduction rescues $\alpha$-synuclein-induced neurodegeneration [15].

In patients with sporadic Parkinson's disease, the total ATP13A2 concentration in substantia nigra is decreased, but it is higher than in healthy controls in the surviving dopaminergic neurons, possibly reflecting its protective role $[8,28]$.

The role of ATP13A2 in pathogenesis of KRS and related syndromes remains unknown, but overall, metal ion transport, mitochondrial dysfunction, lysosomal pathways disturbance and alpha-synuclein metabolism regulation has been implicated $[8,15,17,20,28,34,43,44]$.

KRS was proposed as a new type of neurodegeneration with brain iron accumulation (NBIA) because of basal ganglia MRI T2 hypointensities reported in some cases, but they are actually found in minority of patients. No T2 hypointensitivity and no signal change in either $\mathrm{T}^{*}$ - or susceptibility-weighted imaging were present in our patient. Thus, we found no evidence of iron deposition.

Pathogenic mutations found in KRS, SPG and NCL families are loss-of-function, missense [12,23,30,38] or frameshift resulting in product truncation [33,37]. These mutations lead to transcript instability, product trafficking to a wrong compartment and subsequent proteasomic degradation, or enzymatic inactivity [34]. SPG78 mutations, similarly to the ones causing KRS and neuronal ceroid lipofuscinosis, cause loss of ATP13A2 function due to transcript or protein instability and abnormal intracellular localization of the mutant proteins, ultimately impairing the lysosomal and mitochondrial function. There is also biochemical evidence that disease-causing mutations can affect the catalytic autophosphorylation activity of ATP13A2.

It was suggested that missense mutations tend to be associated with more indolent progression, while truncating variants may, but do not have to, cause a more aggressive course. Our patient, despite carrying two truncating variants, experiences a relatively protracted progression.

\section{Ultrastructural findings}

There is a paucity of pathological studies in KRS. The few available peripheral tissue biopsies show a variety of intracellular osmiophilic depositions. Cytoplasmic inclusion bodies were reported in the Pakistani patient in a sural nerve biopsy obtained at the age of 40 [35]. They resembled irregular primary lysosomes and were found in Schwann cells, perineurial and epineurial cells but not in neurons. Lamellar inclusion bodies were found in the Italian kindred in the skin (fibrocytes, endothelial cells, macrophages) and in myocytes [25]. Abnormal storage material was also present in fibrocytes from SPG78 patients [10].

These observations support the concept of APT13A2-related diseases as a lysosomal storage disease. In fact, an ATP13A2 mutation does cause an adult-onset NCL in Tibetan terriers [11], however, cerebellar ataxia instead of parkinsonism is the associated syndrome in the dog. More recently, a homozygous ATP13A2 mutation was identified in a large Belgian family with juvenile onset NCL [5]. Here, unlike the canine disease, one could notice an actual similarity to KRS. Affected members showed pyramidal signs, cognitive impairment and rigidity-akinesia responsive to levodopa. The index case patient also featured prominent myoclonias and slow vertical ocular movements. This patient died at 34 due to pulmonary embolism. Post-mortem pathological examination showed retinal, cerebral and cerebellar lipofuscinosis with whorled lamellar deposits in neurons and glia.

Our case is one of the few with pathological data available.

An ultrastructural study of our patient's skin and muscle biopsy showed the presence of mixed osmiophilic inclusions - NCL-specific lipopigment deposits, which included homogeneous dark rounded inclusions and heterogeneous deposits with loose texture GROD material and less common fingerprint pro- 
files [1]. The patient's fibroblasts contained lamellar inclusions, while in previous studies, they were found in muscle satellite cells [42]. We also identified "zebra like" inclusions, rounded, membrane-bound bodies with a striped texture; in NCL, similar ones were previously found in Schwann cells [16]. Overall, in our case, the inclusions were observed in various cells, including eccrine sweat glands epithelial cells, intradermal nerve fibres, muscular satellite cells, intramuscular fibroblasts and in small blood vessels, within the endothelium and capillary pericytes.

Neuronal ceroidolipofuscinoses are common hereditary lysosomal storage diseases. At least fourteen types have been described. They are characterized by loss of brain and retinal nerve cells and accumulation of intracellular lipopigment, predominantly in neurons of the central nervous system, but also in other tissues [1].

The composition and origin of the storage material in NCLs are heterogeneous [1]. Above all, it contains ceroid-lipopigments, subunit c of mitochondrial ATP synthase or lysosomal sphingolipid activator proteins A and D. NCL-associated genes (NCL1 to NCL14) encode proteins of various function and intracellular localization.

The location and morphology of the inclusions is just as diverse. Described forms include granular osmiophilic deposits, curvilinear profiles and fingerprint profiles in various combinations [1].

In the analysed case, the highly variable morphology and distribution of inclusion bodies prevent us from defining a pattern pathognomonic for KRS.

\section{Conclusions}

We report two novel causative mutations for the Kufor-Rakeb phenotype of early-onset parkinsonism with pyramidal signs, supranuclear gaze palsy, dementia, psychosis and facial-finger myoclonus, incorporating unusual features of ataxia and polyneuropathy. We provide ultrastructural assessment with evidence of osmiophilic NCL-like deposits and confirm a meaningful response to levodopa.

Since the discovery of ATP13A2's causative role in KRS, new mutations have continued to be identified. The phenotype spectrum spans from those resembling the atypical parkinsonism of original KRS descriptions, through neuronal ceroid lipofuscinosis [5], to SPG type 78 with pyramidal-cerebellar syndrome but essentially no parkinsonism [10], and to relatively uncomplicated early - $[6,12,24,26]$ as well as late-onset Parkinson's disease [36].

Overall, our patient appears to combine a typical KRS phenotype with both the cerebellar syndrome (along with considerable cerebellar atrophy) and peripheral nerve involvement, resembling an overlap of KRS and SPG78.

\section{Disclosure}

The authors report no conflict of interest.

\section{References}

1. Anderson GW, Goebel HH, Simonati A. Human pathology in NCL. Biochim Biophys Acta 2013; 1832: 1807-1826.

2. Behrens MI, Brüggemann N, Chana P, Venegas P, Kägi M, Parrao T, Orellana P, Garrido C, Rojas CV, Hauke J, Hahnen E, González R, Seleme N, Fernández V, Schmidt A, Binkofski F, Kömpf D, Kubisch C, Hagenah J, Klein C, Ramirez A. Clinical spectrum of Kufor-Rakeb syndrome in the Chilean kindred with ATP13A2 mutations. Mov Disord 2010; 25: 1929-1937.

3. Blueprint Genetics. Comprehensive Metabolism Pane 2017, version 2, Aug 14, 2017. https://blueprintgenetics.com/tests/ panels/metabolic-disorders/comprehensive-metabolism-panel/

4. Bouhouche A, Tesson C, Regragui W, Rahmani M, Drouet V, Tibar H, Souirti Z, Ben El Haj R, Bouslam N, Yahyaoui M, Brice A, Benomar A, Lesage S. Mutation analysis of consanguineous Moroccan patients with Parkinson's disease combining microarray and gene panel. Front Neurol 2017; 8: 1-11.

5. Bras J, Verloes A, Schneider SA, Mole SE, Guerreiro RJ. Mutation of the parkinsonism gene ATP13A2 causes neuronal ceroidlipofuscinosis. Hum Mol Genet 2012; 21: 2646-2650.

6. Chen CM, Lin CH, Juan HF, Hu FJ, Hsiao YC, Chang HY, Chao CY, Chen IC, Lee LC, Wang TW, Chen YT, Chen YT, Lee-Chen GJ, Wu YR. ATP13A2 variability in Taiwanese Parkinson's disease. Am J Med Genet Part B Neuropsychiatr Genet 2011; 156: 720729.

7. Crosiers D, Ceulemans B, Meeus B, Nuytemans K, Pals P, Van Broeckhoven C, Cras P, Theuns J. Juvenile dystonia-parkinsonism and dementia caused by a novel ATP13A2 frameshift mutation. Park Relat Disord 2011; 17: 135-138.

8. Dehay B, Ramirez A, Martinez-Vicente M, Perier C, Canron M-H, Doudnikoff E, Vital A, Vila M, Klein C, Bezard E. Loss of P-type ATPase ATP13A2/PARK9 function induces general lysosomal deficiency and leads to Parkinson disease neurodegeneration. Proc Natl Acad Sci U S A 2012; 109: 9611-9616.

9. Eiberg H, Hansen L, Korbo L, Nielsen I, Svenstrup K, Bech S, Pinborg L, Friberg L, Hjermind L, Olsen O, Nielsen J. Novel mutation in ATP13A2 widens the spectrum of Kufor-Rakeb syndrome (PARK9). Clin Genet 2012; 82: 256-263.

10. Estrada-Cuzcano A, Martin S, Chamova T, Synofzik M, Timmann D, Holemans T, Andreeva A, Reichbauer J, De Rycke R, Chang DI, Van Veen S, Samuel J, Schöls L, Pöppel T, Sørensen DM, Asselbergh B, Klein C, Zuchner S, Jordanova A, Van- 
gheluwe P, Tournev I, Schüle R. Loss-of-function mutations in the ATP13A2/PARK9 gene cause complicated hereditary spastic paraplegia (SPG78). Brain 2017; 140: 287-305.

11. Farias FHG, Zeng R, Johnson GS, Wininger FA, Taylor JF, Schnabel RD, McKay SD, Sanders DN, Lohi H, Seppälä EH, Wade CM, Lindblad-Toh K, O'Brien DP, Katz ML. A truncating mutation in ATP13A2 is responsible for adult-onset neuronal ceroid lipofuscinosis in Tibetan terriers. Neurobiol Dis 2011; 42: 468-474.

12. Di Fonzo A, Chien HF, Socal M, Giraudo S, Tassorelli C, lliceto G, Fabbrini G, Marconi R, Fincati E, Abbruzzese G, Marini P, Squitieri F, Horstink MW, Montagna P, Libera AD, Stocchi F, Goldwurm S, Ferreira JJ, Meco G, Martignoni E, Lopiano L, Jardim LB, Oostra BA, Barbosa ER, Bonifati V, Bonifati V, Vanacore N, Meco G, Fabbrini G, Fabrizio E, Locuratolo N, Scoppetta C, Manfredi M, Berardelli A, Lopiano L, Giraudo S, Bergamasco B, Pacchetti C, Nappi G, Antonini A, Pezzoli G, Riboldazzi G, Bono G, Raudino F, Manfredi M, Fincati E, Tinazzi M, Bonizzato A, Ferracci C, Dalla Libera A, Abbruzzese G, Marchese R, Montagna P, Marini P, Massaro F, Guidi M, Minardi C, Rasi F, Onofrj M, Thomas A, Stocchi F, Vacca L, De Pandis F, De Mari M, Diroma C, Iliceto G, Lamberti P, Toni V, Trianni G, Mauro A, De Gaetano A, Rizzo M, Cossu G, Rieder CRM, Saraiva-Pereira ML. ATP13A2 missense mutations in juvenile parkinsonism and young onset Parkinson disease. Neurology 2007; 68: 1557-1562.

13. Fung VS, Mehta P, Manwaring N, Sue CM, Kubisch C. Clinical, neurophysiological and genetic observations in Kufor-Rakeb syndrome: report of a new kindred with compound heterozygous mutations in the ATP13A2 gene. J Clin Neurosci 2008; 16: 466.

14. Gibbs RA, Boerwinkle E, Doddapaneni H, Han Y, Korchina V, Kovar C, ..., Rasheed A. A global reference for human genetic variation. Nature 2015; 526: 68-74.

15. Gitler AD, Chesi A, Geddie ML, Strathearn KE, Hamamichi S, Hill KJ, Caldwell KA, Caldwell GA, Cooper AA, Rochet J-C, Lindquist S. $\alpha$-Synuclein is part of a diverse and highly conserved interaction network that includes PARK9 and manganese toxicity. Nat Genet 2009; 41: 308-315.

16. Goebel HH, Zeman W, Pilz H. Ultrastructural investigations of peripheral nerves in neuronal ceroid-lipofuscinoses (NCL). J Neurol 1976; 213: 295-303.

17. Grünewald A, Arns B, Seibler P, Rakovic A, Münchau A, Ramirez A, Sue CM, Klein C. ATP13A2 mutations impair mitochondrial function in fibroblasts from patients with Kufor-Rakeb syndrome. Neurobiol Aging 2012; 33: 1843.e1-1843.e7.

18. Kaul A, Franzese K, Cohen J. Poster 298 Ataxia and dysarthria in two siblings with Kufor-Rakeb syndrome: A case report. PM R 2016; 8 (9 Suppl): S257.

19. Kertelge L, Brüggemann N, Schmidt A, Tadic V, Wisse C, Dankert S, Drude L, van der Vegt J, Siebner H, Pawlack H, Pramstaller PP, Behrens MI, Ramirez A, Reichel D, Buhmann C, Hagenah J, Klein C, Lohmann K, Kasten M. Impaired sense of smell and color discrimination in monogenic and idiopathic Parkinson's disease. Mov Disord 2010; 25: 2665-2669.

20. Kong SMY, Chan BKK, Park JS, Hill KJ, Aitken JB, Cottle L, Farghaian H, Cole AR, Lay PA, Sue CM, Cooper AA. Parkinson's disease-linked human PARK9/ATP13A2 maintains zinc homeo- stasis and promotes $\alpha$-Synuclein externalization via exosomes. Hum Mol Genet 2014; 23: 2816-2833.

21. Landrum MJ, Lee JM, Benson M, Brown GR, Chao C, Chitipiralla S, Gu B, Hart J, Hoffman D, Jang W, Karapetyan K, Katz K, Liu C, Maddipatla Z, Malheiro A, McDaniel K, Ovetsky M, Riley G, Zhou G, Holmes JB, Kattman BL, Maglott DR. ClinVar: improving access to variant interpretations and supporting evidence. Nucleic Acids Res 2018; 46: D1062-D1067.

22. Lek M, Karczewski KJ, Minikel EV, Samocha KE, Banks E, Fennell T, O'Donnell-Luria AH, Ware JS, Hill AJ, Cummings BB, Tukiainen T, Birnbaum DP, Kosmicki JA, Duncan LE, Estrada K, Zhao F, Zou J, Pierce-Hoffman E, Berghout J, Cooper DN, Deflaux N, De Pristo M, Do R, Flannick J, Fromer M, Gauthier L, Goldstein J, Gupta N, Howrigan D, Kiezun A, Kurki MI, Moonshine AL, Natarajan P, Orozco L, Peloso GM, Poplin R, Rivas MA, Ruano-Rubio V, Rose SA, Ruderfer DM, Shakir K, Stenson PD, Stevens C, Thomas BP, Tiao G, Tusie-Luna MT, Weisburd B, Won H-H, Yu D, Altshuler DM, Ardissino D, Boehnke M, Danesh J, Donnelly S, Elosua R, Florez JC, Gabriel SB, Getz G, Glatt SJ, Hultman CM, Kathiresan S, Laakso M, McCarroll S, McCarthy MI, McGovern D, McPherson R, Neale BM, Palotie A, Purcell SM, Saleheen D, Scharf JM, Sklar P, Sullivan PF, Tuomilehto J, Tsuang MT, Watkins HC, Wilson JG, Daly MJ, MacArthur DG, Consortium EA. Analysis of protein-coding genetic variation in 60,706 humans. Nature 2016; 536: 285-291.

23. Lin CH, Tan EK, Chen ML, Tan LC, Lim HQ, Chen GS, Wu RM. Novel ATP13A2 variant associated with Parkinson disease in Taiwan and Singapore. Neurology 2008; 71: 1727-1732.

24. Malakouti-Nejad M, Shahidi GA, Rohani M, Shojaee SM, Hashemi M, Klotzle B, Fan JB, Elahi E. Identification of p.G $\ln 858^{*}$ in ATP13A2 in two EOPD patients and presentation of their clinical features. Neurosci Lett 2014; 577: 106-111.

25. Malandrini A, Rubegni A, Battisti C, Berti G, Federico A. Electron-dense lamellated inclusions in 2 siblings with Kufor-Rakeb syndrome. Mov Disord 2013; 28: 1751-1752.

26. Mao XY, Burgunder JM, Zhang ZJ, Chang XL, Peng R, Burgunder JM, Yang Y, Wang YC, Li T, Zhang ZJ. ATP13A2 G2236A variant is rare in patients with early-onset Parkinson's disease and familial Parkinson's disease from mainland China. Park Relat Disord 2010; 16: 235-236.

27. Martino D, Melzi V, Franco G, Kandasamy N, Monfrini E, Di Fonzo A. Juvenile dystonia-parkinsonism syndrome caused by a novel p.S941Tfs1X ATP13A2 (PARK9) mutation. Park Relat Disord 2015; 21: 1378-1380.

28. Murphy KE, Cottle L, Gysbers AM, Cooper AA, Halliday GM. ATP13A2 (PARK9) protein levels are reduced in brain tissue of cases with Lewy bodies. Acta Neuropathol Commun 2013; 1: 11.

29. Najim Al-Din AS, Wriekat A, Mubaidin A, Dasouki M, Hiari M. Pallido-pyramidal degeneration, supranuclear upgaze paresis and dementia: Kufor-Rakeb syndrome. Acta Neurol Scand 1994; 89: 347-352.

30. Ning YP, Kanai K, Tomiyama H, Li Y, Funayama M, Yoshino H, Sato S, Asahina M, Kuwabara S, Takeda A, Hattori T, Mizuno Y, Hattori N. PARK9-linked parkinsonism in eastern Asia: mutation detection in ATP13A2 and clinical phenotype. Neurology 2008; 70 (16 Pt 2): 1491-1493. 
31. Paisán-Ruiz C, Guevara R, Federoff M, Hanagasi H, Sina F, Elahi E, Schneider SA, Schwingenschuh P, Bajaj N, Emre M, Singleton AB, Hardy J, Bhatia KP, Brandner S, Lees AJ, Houlden H. Early-onset L-dopa-responsive Parkinsonism with pyramidal signs due to ATP13A2, PLA2G6, FBXO7 and Spatacsin mutations. Mov Disord 2010; 25: 1791-1800.

32. Park J-S, Blair NF, Sue CM. The role of ATP13A2 in Parkinson's disease: Clinical phenotypes and molecular mechanisms. Mov Disord 2015; 30: 770-779.

33. Park JS, Mehta P, Cooper AA, Veivers D, Heimbach A, Stiller B, Kubisch C, Fung VS, Krainc D, Mackay-Sim A, Sue CM. Pathogenic effects of novel mutations in the P-type ATPase ATP13A2 (PARK9) causing Kufor-Rakeb syndrome, a form of early-onset parkinsonism. Hum Mutat 2011; 32: 956-964.

34. Podhajska A, Musso A, Trancikova A, Stafa K, Moser R, Sonnay S, Glauser L, Moore DJ. Common pathogenic effects of missense mutations in the P-type ATPase ATP13A2 (PARK9) associated with early-onset parkinsonism. PLoS One 2012; 7: e39942.

35. Quinn NP, Goadsby PJ, Lees AJ. Hereditary juvenile parkinsonism with pyramidal signs and mental retardation. Eur J Neurol 1995; 2: 23-26.

36. Rakovic A, Stiller B, Djarmati A, Flaquer A, Freudenberg J, Toliat MR, Linnebank M, Kostic V, Lohmann K, Paus S, Nürnberg P, Kubisch C, Klein C, Wüllner U, Ramirez A . Genetic association study of the P-type ATPase ATP13A2 in late-onset Parkinson's disease. Mov Disord 2009; 24: 429-433.

37. Ramirez A, Heimbach A, Gründemann J, Stiller B, Hampshire D, Cid LP, Goebel I, Mubaidin AF, Wriekat AL, Roeper J, Al-Din A, Hillmer AM, Karsak M, Liss B, Woods CG, Behrens MI, Kubisch C, Ramirez, A; Heimbach, A; Grundemann J. Hereditary parkinsonism with dementia is caused by mutations in ATP13A2, encoding a lysosomal type 5 P-type ATPase. Nat Genet 2006; 38: 1184-1191.

38. Santoro L, Breedveld GJ, Manganelli F, lodice R, Pisciotta C, Nolano M, Punzo F, Quarantelli M, Pappatà S, Di Fonzo A, Oostra BA, Bonifati V. Novel ATP13A2 (PARK9) homozygous mutation in a family with marked phenotype variability. Neurogenetics 2011; 12: 33-39.

39. Schmidt K, Wolfe DM, Stiller B, Pearce DA. Cd(2+), Mn(2+), $\mathrm{Ni}(2+)$ and $\mathrm{Se}(2+)$ toxicity to Saccharomyces cerevisiae lacking YPK9p the orthologue of human ATP13A2. Biochem Biophys Res Commun 2009; 383: 198-202.

40. Schneider SA, Paisan-Ruiz C, Quinn NP, Lees AJ, Houlden H, Hardy J, Bhatia KP. ATP13A2 mutations (PARK9) cause neurodegeneration with brain iron accumulation. Mov Disord 2010; 25: 979-984.

41. Stenson PD, Ball EV, Mort M, Phillips AD, Shiel JA, Thomas NST, Abeysinghe S, Krawczak M, Cooper DN. Human Gene Mutation Database (HGMD®): 2003 update. Hum Mutat 2003; 21: 577 581.

42. Tome FM, Brunet P, Fardeau M, Hentati F, Reix J. Familial disorder of the central and peripheral nervous systems with particular cytoplasmic lamellated inclusions in peripheral nerves, muscle satellite cells, and blood capillaries. Acta Neuropathol 1985; 68: 209-217.
43. Usenovic M, Tresse E, Mazzulli JR, Taylor JP, Krainc D. Deficiency of ATP13A2 leads to lysosomal dysfunction, $\alpha$-synuclein accumulation and neurotoxicity. J Neurosci 2012; 32: 4240-4246.

44. van Veen S, Sørensen DM, Holemans T, Holen HW, Palmgren MG, Vangheluwe P. Cellular function and pathological role of ATP13A2 and related P-type transport ATPases in Parkinson's disease and other neurological disorders. Front Mol Neurosci 2014; 7: 1-22.

45. Williams DR, Hadeed A, Najim al-Din AS, Wreikat AL, Lees AJ. Kufor Rakeb disease: Autosomal recessive, levodopa-responsive Parkinsonism with pyramidal degeneration, supranuclear gaze palsy, and dementia. Mov Disord 2005; 20: 1264-1271. 